\title{
LOS SUEÑOS DE LA RAZÓN
}

Consideraciones sobre las imágenes de monstruos en el antiguo Egipto

Sebastián F. Maydana 


\section{Sebastián Francisco Maydana}

Instituto de Historia Antigua Oriental "Dr. Abraham Rosenvasser"

Facultad de Filosofía y Letras, Universidad de Buenos Aires

\section{Los sueños de la razón. Consideraciones sobre las imágenes de} monstruos en el antiguo Egipto

\section{DOI: $10.36446 /$ be.2020.52.218}

\section{Resumen}

The Origins of Monsters. Image and Cognition in the First Age of Mechanical Reproduction (2014), de David Wengrow, entrelaza hábilmente ideas de diversas disciplinas para responder una inquietud de la historia antigua: por qué las imágenes monstruosas parecen transmitirse más fácilmente que otras. La reciente reedición del libro es una ocasión propicia para recuperar y discutir algunas de sus propuestas y argumentos. Mediante el concurso de ciertas imágenes "monstruosas" producidas en el Egipto Predinástico, se revisarán algunas hipótesis de Wengrow para las cuales no presenta más evidencia que su intuición.

\section{Palabras clave}

David Wengrow; Reproducción Técnica; Híbridos; Egipto Predinástico; Arte Rupestre

\section{Dreams of reason. Some remarks on monstrous images in ancient Egypt}

\section{Abstract}

David Wengrow's The Origins of Monsters. Image and Cognition in the First Age of Mechanical Reproduction (2014) skillfully weaves together ideas from diverse disciplines to answer a problem from ancient history: why monstrous images seem to be more easily transmitted than others. Its recent re-edition provides the propitious occasion to rethink and discuss some of its proposals and arguments. Through certain "monstrous" images produced in Predynastic Egypt, some Wengrow's hypotheses, for which he does not provide further evidence than his intuition, will be reviewed.

\section{Keywords}

David Wengrow; Technical Reproduction; Hybrids; Predynastic Egypt; Rock Art

Recibido: 10/06/20. Aprobado: 07/09/20.
1. Jacques Derrida discutió en varias ocasiones, y más aun notablemente en su conferencia sobre "La mano de Heidegger" (2012 [1990]), la etimología de la palabra "monstruo". Derrida la emparenta con la familia de "mostrar" (en latín monstro), pero realmente proviene de moneo (advertir, aconsejar), y sólo posteriormente el sustantivo monstrum devino en monstro. Pero establecer la secuencia etimológica en la lengua latina es una cosa y explicar su semántica es un problema bien distinto. ¿En qué punto de los siguientes milenios se originó el significado que el uso actual le da a la palabra monstruo?

Precisamente sobre los orígenes de este término trata el último libro de David Wengrow, The Origins of Monsters. Image and Cognition in the First Age of Mechanical Reproduction (2014), que ha sido recientemente reeditado. Si en los siguientes párrafos me he propuesto hacerlo objeto de mis críticas no es con ánimo de señalar sus defectos sino precisamente en honor a su principal virtud: el ser una obra provocadora y generadora de pensamiento. Las ideas que presenta son frescas y originales, y merecen ser pensadas y discutidas. Hacerlo, aun disintiendo en muchos aspectos, no debe ser entendido sino como un homenaje y un reconocimiento.

Entonces, lo primero que me gustaría hacer es recuperar algunas de estas ideas y argumentos, para confrontarlas con cierta evidencia que Wengrow no analizó. En particular, me gustaría traer a la discusión algunas imágenes "monstruosas" producidas en el antiguo

Boletín de Estética 52: 7-44, 2020

ISSN 2408-4417 (online) | DOI: 10.36446/be.2020.52.218 
Egipto, no mucho tiempo antes de que comenzara la "época de la reproductibilidad técnica", así como herramientas críticas de la historia del arte. En segundo término, tomaré algunas de sus hipótesis propuestas hacia el final del texto, para las cuales no presenta más evidencia que su intuición. Intentaré llevar adelante su argumento, a fin de evaluar su plausibilidad, y continuarlo agregando ideas propias surgidas de mi investigación. Como se verá, los puntos de partida de Wengrow lo habilitan a continuar la línea de investigación por dos caminos divergentes, forzando al arqueólogo a escoger. Finalizaré mi recorrido explorando el camino alternativo y, espero, demostrando que se ciñe más a la evidencia iconográfica disponible en el valle del Nilo.

Retomando las disquisiciones lingüísticas, nuestra pregunta de partida, entonces, debería ser: los monstruos predinásticos ¿nos están mostrando algo o más bien presagian algún grave acontecimiento? Antes de entrar de lleno en el contenido del libro de Wengrow, es preciso señalar que su título es intrigante pero engañoso. $Y$ considero que la mejor forma de analizarlo es descomponiéndolo en módulos.

2. Toda obra tiene un origen, un acontecimiento que la provoca. El de este libro fue la convocatoria recibida por Wengrow para participar de las Rostovtzeff Lectures, clases magistrales basadas en algún aspecto de la obra de Mijail Rostovtzeff. El historiador ruso exiliado se especializó en historia económica, y su punto de partida naturalmente era opuesto al marxismo. Así, tendía a considerar el mercado como una fuerza extrahumana y a los seres humanos como actuando mediante una racionalidad exacerbada. Para él, la clave de la economía no estaba en los actores individuales sino precisamente en el intercambio, dominado desde siempre por las leyes del mercado. Si bien estas ideas pueden parecer superadas, Wengrow se dio cuenta que Rostovtzeff fue el primero en señalar la relación entre el urbanismo y el intercambio cultural de imágenes de criaturas fantásticas (Wengrow 2014: 6). A partir de ello se dio cuenta de que las tesis de Rostovtzeff merecían una revisión crítica, y sobre todo que no eran incompatibles con algunas ideas que el investigador venía barajando por lo menos desde hacía una década (Wengrow 2017: 2).

Y aquí está el primer engaño del libro. Porque al estilo del historiador ruso, Wengrow no va a estudiar específicamente los orígenes de los monstruos sino los mecanismos de su "transmisión". Para ello, se apoya en la idea de la "epidemiología de la cultura" (Sperber 1985), una teoría que contra lo que podría intuirse no afirma una esencia viral de la cultura, sino que toma su nombre de los métodos que usan los epidemiólogos y los aplica al estudio de la transmisión de ciertos motivos culturales. Así, la primera propuesta arriesgada que hace Wengrow es que algunas imágenes de animales híbridos pueden estudiarse desde el punto de vista epidemiológico, pensado en un primer momento sólo para el ámbito de lo narrativo.

El método epidemiológico le resulta atractivo porque permite vincular en un mismo esquema explicativo los movimientos a macroescala poblacional con procesos cognitivos que ocurren en cada individuo. Por ello es que Wengrow recurre también a la psicología cognitiva, especialmente en algunas de sus investigaciones que parecen señalar que "nuestra percepción cotidiana del mundo se forma a partir de un patrón modular de cognición” (2014: 21) ${ }^{1}$. Así, los monstruos no serían seres del todo fantásticos sino recombinaciones de módulos ya conocidos, no por la experiencia cotidiana sino destilados a partir de un conocimiento innato que compone la "bio-

${ }^{1}$ Todas las traducciones de Wengrow son propias. 
logía vulgar" [folk biology] (Wengrow 2014: 20). Un grifo, por ejemplo, es un reensamblaje de rasgos intuitivos (cabeza de ave, cuerpo de león) en un cuerpo (mínimamente) contraintuitivo. Sigue Wengrow:

en tanto imágenes mínimamente contraintuitivas, estas constituyen puntos de referencia privilegiados para ideas acerca de lo sobrenatural, capaces de cruzar las fronteras culturales y de actuar como vehículos para una variedad de discursos rituales, teológicos y mitológicos. (2014: 24)

Este hecho, precisamente, es el que haría que los monstruos sean especialmente propicios para ser transmitidos. En efecto, los monstruos preexisten a los compuestos que estudia Wengrow, y éste dedica el Capítulo 3 (2014: 34-50) a estudiar los animales contraintuitivos paleolíticos y a explicar por qué no los tiene en cuenta para su análisis. No sólo son claramente excepcionales dentro de un corpus de imágenes plagado de ilustraciones realistas (Wengrow 2011a: 155; 2014: 37), sino que no parecen haber sido transmitidos con la misma velocidad.

3. A poco de comenzar el argumento, nos enteramos que Wengrow tampoco hablará de "monstruos", prefiriendo el término "compuestos" [composites] (2014: 25). Si bien puede parecer a simple vista que, independientemente de la palabra que utilice, el lector sabrá exactamente de qué está hablando, hay una razón lógica por la que prefiere hablar de compuestos: porque le permite resaltar que se trata, como acabamos de ver, de ensamblajes a partir de elementos diversos y heterogéneos, aunque siempre con un prototipo en el mundo visible (2014: 26-27). Veremos luego que también defiende el carácter imaginario de estos compuestos, pero la imaginación a la que se refiere Wengrow es una que ensambla, no una que inventa. Como dirían Ingold y Hallam, una imaginación que innova, no una que improvisa (2007: 19).

De todas maneras, el nombre sigue pareciendo arbitrario y la justificación, insuficiente. En uno de los artículos previos a la escritura del libro, Wengrow admite que la utilización de la palabra "monstruos" obedece a razones publicitarias: "mi título es puramente para causar efecto" (2011a: 154) ¿Por qué no hablar, por ejemplo, de quimeras? Carlo Severi las define de la siguiente manera: "la asociación, en una sola imagen, de rasgos heterogéneos provenientes de diversos organismos" (2004: 63). Esta noción es más plástica, porque al hablar de "rasgos" no se tiene en cuenta solamente los caracteres anatómicos sino que en forma amplia se podrían incluir toda clase de asociaciones contenidas en el cuerpo hibridado de la quimera. A Severi le interesa más el proceso mental de desciframiento y la utilización de las quimeras como dispositivos de memoria que su transmisión cultural. La quimera es un misterio para aquellos que no participan del universo cultural que las creó; los compuestos, un continente que puede ser decodificado y apropiado por diversos y heterogéneos conjuntos humanos.

¿Qué son, entonces, los híbridos? Wengrow utiliza este vocablo esporádicamente, en principio como sinónimo de compuesto, pero el contexto en que lo hace es revelador. Al referirse a algunos objetos egipcios del Predinástico que presentan vagamente formas animales o humanas pero cuya identificación es dificultosa, hace el siguiente comentario:

Los híbridos predinásticos más tempranos no resultan de una división y recombinación sistemática de partes corporales estandarizadas. Más bien parecen surgir de un juego re- 
flexivo sobre similitudes en la apariencia de varias especies, lo cual resulta en un modo de representación que se resiste a los modernos intentos de clasificación. (Wengrow 2014: 49)

La diferencia entonces entre estos híbridos y los compuestos de Wengrow es que los primeros parecen ser voluntariamente inclasificables, un animal sui generis. Es precisamente por ello que prefiero hablar de híbridos, una categoría menos restrictiva. Los híbridos del Egipto Predinástico, en este sentido, se parecen más a las quimeras de Severi y Dimitri Karadimas en que el fundamento de su potencia está en la incompletitud, en el otorgar pistas visibles para que el espectador construya sus propias imágenes mentales, y no en las variaciones mínimas a partir de un todo coherente asociado a ciertas expectativas innatas. Un ejemplo material nos permitirá entender un poco más esta diferencia, en mi opinión no despreciable.

Tomemos, entonces, el mango de cuchillo de Abu Zeidan [fig. 1]. Se trata de un artefacto bien conocido, no sólo debido a la belleza intrínseca de su confección sino al hecho que fue descubierto hace ya más de un siglo por Henri De Morgan (1909: 274-278). Desde ese momento, fueron varios los egiptólogos que se propusieron describir las especies animales que aparecen en las veinte hileras (diez de cada lado) que ostenta el mango. La mayoría fueron exitosamente identificadas, pero una hilera en particular, la A7, presenta una serie de bestias que parecen resistirse a la descripción (Churcher 1984: 159). No quisiera detenerme en la cronología de estos intentos (al respecto véase Huyge 2004: 824-826), baste nombrar algunos de los animales propuestos: puercoespín, erizo, hiena, etc. El principal problema lo presenta lo que parece ser una aleta dorsal a lo largo del lomo del cuadrúpedo, y tuvieron que pasar casi cien años hasta que Dirk Huyge proponga que no se trataba de ningún animal conocido, sino de un híbrido entre antílope y pez (2004).
Una solución que antes parecía descabellada, ahora es ampliamente aceptada.

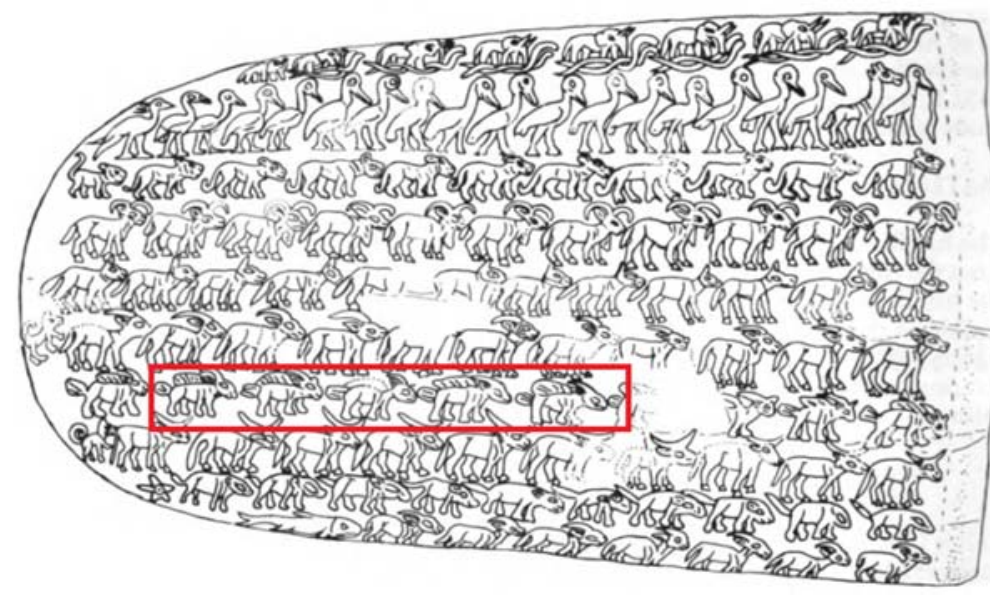

Figura 1: mango de cuchillo de Abu Zeidan (modificado de Churcher 1984: fig. 34). Brooklyn Museum of Art, Acc. No. 09.889.118

El episodio ilustra a la perfección la obsesión por la identificación que ha marcado la historia de la disciplina. Y se trata de una cuestión peligrosa, decía, porque se pierde demasiado tiempo en discusiones estériles y se termina ocultando el verdadero problema: el de la hibridez.

Pensar en términos de hibridez ${ }^{2}$, permite reconocer que no se trata de un animal intuitivo, ni siquiera de una combinación de partes de

${ }^{2}$ No se me escapa que la idea de hibridez ha sido utilizada extensamente por los estudios decoloniales, específicamente en las obras de Homi Bhabha (e.g. 1994), pero la entienden de forma inversa. Para ellos, la hibridez es una situación en la que no se llega a construir una identidad propia, sino que se mantiene parte de la ideología dominante, un in-between, mientras que en el sentido que la tomo yo un híbrido es siempre más que la suma de sus partes. 
distintos animales, sino de algo completamente nuevo (Karadimas 2015). Este tipo de imágenes requieren que nos concentremos no en reconocer elementos (módulos) esperables, sino más bien que prestamos atención a las ambigüedades, que evitemos las definiciones rígidas. Sólo así podremos comprender la hibridez de estas imágenes y ver las quimeras que nadie vio, como en el caso del cuchillo de Abu Zeidan.

Para terminar de ilustrar esta discusión mediante un ejemplo lejano, en el Valle de Ambato en la provincia de Catamarca (República Argentina) se han estudiado imágenes de híbridos en cerámicas del Período de Desarrollos Regionales (ca. 900-1480 d.C.). Un motivo bastante común en estas cerámicas es un felino que posee atributos tanto del puma como del jaguar (Bovisio 2008: 17). Ahora bien, el puma puede ver en la oscuridad y trepar árboles, mientras que el jaguar puede nadar. Así, el híbrido que incorpora rasgos de estos dos animales no sólo posee las potencias de ambos combinadas, sino que se convierte en una metáfora del hábil cazador que puede perseguir a su presa en cualquier medio en que ella esté. Llamar compuesto a este motivo le quitaría parte de su riqueza simbólica y oscurecería buena parte de lo que nos puede decir acerca de la organización social de los pobladores del Ambato.

4. Cuando rechaza continuar refiriéndose a los compuestos como "monstruos", Wengrow agrega que también hablará de "imágenes" en lugar de "representaciones", en sus palabras, "porque al hablar de compuestos me refiero en todos los casos a criaturas de la imaginación, y no imágenes de cosas vivas visibles en el mundo" (2014: 25). Esta distinción no tiene sustento en ninguna postura teórica, sino simplemente en una similitud fonética azarosa entre imagen e imaginación. Podemos decir algunas palabras al respecto desde la historia del arte, una disciplina sorprendentemente soslayada por Wengrow, más allá de algunos comentarios superficiales.

En cuanto a la imaginación como opuesta a la representación, recordemos que el antropólogo del arte Hans Belting ha señalado:

una imagen encuentra su verdadero sentido en representar algo que está ausente, por lo que sólo puede estar ahí en la imagen; hace que aparezca algo que no está en la imagen, sino que solo puede aparecer en la imagen. (2007: 178)

Por ello, la creación de imágenes se relaciona para Belting con una función cognitiva del ser humano que es la memoria (Belting 2009 [1990]: 19; Severi 2004), y en particular la memoria de alguien fallecido (Belting 2005: 307). La imagen para Belting tiene en sus orígenes la utilidad de traer a la memoria a quien está físicamente ausente, frecuentemente un antepasado. De ahí la idea que Wengrow quiere combatir: la re-presentación como "volver a presentar" algo del pasado.

Ernst Gombrich (1982 [1974]), por su parte, señala que se tiende a entender las representaciones visuales o bien como mapas o bien como espejos. La representación-mapa da "información selectiva sobre el mundo físico", mientras que la representación-espejo busca "presentar la apariencia de un aspecto del mundo" (1982 [1974]). Para ninguna de las dos posturas existe por lo tanto una correlación fija entre el mundo óptico y el mundo de nuestra experiencia visual, pero en definitiva, la razón de ser de la imagen sigue siendo puramente informativa.

En defensa de Wengrow, hay otra forma de pensar la imagen (cf. Maidana 2018), una que le otorga importancia a la imaginación 
como proceso mental y no mecánico. Esta postura, ejemplificada en el llamado Giro Icónico (Moxey 2008), piensa la imagen como un ámbito autónomo del lenguaje y también coloca el sentido de ésta no en una ausencia, sino justamente en ser presencia (Bovisio 2011). Es decir que la imagen presentifica algo que no tiene por qué estar ausente (y que quizás nunca haya existido):

Toda imagen plástica tiene su origen en una experiencia de la realidad física circundante, lo que no quiere decir que refleja o describe cosas reales sino que se funda en la experiencia perceptiva que los hombres tienen de su entorno, articulando lo percibido con lo conocido y lo imaginado. (Bovisio 2011)

La autora introduce un tercer término que se superpone a lo percibido (por medio de los sentidos) y a lo conocido (recordado). Para ella, la relación del hombre con el mundo no-humano es "racional y emocional, cognitiva y sensitiva" (Bovisio 2008: 3).

Creo que el primer historiador del arte en mencionar seriamente la importancia de la imaginación humana fue Pierre Francastel (1970), quien propuso la existencia de un "pensamiento plástico" o una "intuición estética", irreductible al lenguaje, encarnado en imágenes que por su propia naturaleza crean mundos. En este sentido señala que "La intuición estética descansa sobre una problemática de lo imaginario, y de ningún modo sobre el inventario de algún universo sensible o mental susceptible de ser englobado en un sistema cualquiera" (1970: 29). Según él, la obra de arte no remite a un "universo de formas inmutablemente recortadas, sino que desencadena un proceso de representación dialéctica entre lo percibido, lo real y lo imaginario" (1970: 30). Dos precisiones se pueden decir acerca de esta afirmación: en primer lugar, que en ningún momento hace referencia a la psicología cognitiva, sólo a la relación sensorial entre ser humano y entorno; y en segundo lugar, que en la distinción que hace se adivina la misma operación que lleva a Tim Ingold a rechazar el modelo hilemórfico (es decir, el que concibe la creación material, artística o de otra índole, como la mera aplicación de un modelo preestablecido en la mente del creador) en favor de uno ontogenético que tenga en cuenta el carácter imprevisto de la creación (y de la imaginación) y su papel constitutivo de la persona, que se realiza en el hacer y en el relacionarse con otros (Ingold 2012: 432-433).

Como vemos, lejos de ser una elección trivial, hay razones profundas para hablar de presentificación y no de representación, y para hacer hincapié en la imaginación de las personas creadoras y receptoras de imágenes. Y no sólo no es trivial, sino que tratarla como tal es peligroso. Dentro del campo de la psicología cognitiva existe una fuerte tendencia a pensar la transmisión cultural como la conversión "en comportamiento corporal" (Sperber 1996: 61) de esquemas que ya están replicados en el cerebro de cada una de las personas como información genética. Pero aunque estas ideas están cuestionadas desde hace algunos años (Lewens 2012: 464), este es el sentido que rescata Wengrow en su trabajo, y por ello afirma siguiendo a Sperber que los híbridos se dispersan debido a cualidades inherentes a los mismos que los hacen proclives a ser transmitidos. Sin embargo, y este es uno de los claros avances de su libro, no se transmiten por ser, en su carácter de representaciones contra-intuitivas, estimulantes para los seres humanos (Sperber 1996: 140), sino porque encuentran en los ámbitos urbanos las condiciones necesarias para esa transmisión, a saber, la habilidad para reproducir mecánicamente las imágenes (Wengrow 2011b: 133; 2014: 73). Sin embargo, esta aparente crítica al modelo epidemiológico cae en la misma trampa cuando olvida que "la gente real, en tanto que organismos 
vivos, se crean a sí mismos y entre sí constantemente, forjando sus historias y tradiciones a cada paso" (Ingold y Hallam 2007: 6). Ingold y Hallam incluyen en su esquema la imaginación como improvisación frente a un mundo permanentemente cambiante, y más adelante veremos de qué manera este modelo se presenta como más apropiado para estudiar la constitución y transmisión de imágenes de híbridos.

5. Wengrow comienza su obra con las siguientes palabras:

La primera época de la reproductibilidad técnica perteneció a Mesopotamia y al notable florecimiento de la vida urbana que tuvo lugar allí hace unos seis mil años. Su impacto en la cultura visual y en la historia del diseño ha pasado desapercibido. El famoso ensayo de Walter Benjamin (1936) La obra de arte en la época de su reproductibilidad técnica no fue más allá de los bronces, terracotas y monedas de los antiguos griegos. (2014: 1)

Es cierto que Benjamin abrió la posibilidad de que haya habido técnicas de reproducción mecánicas anteriores al cine y la fotografía, pero sus palabras, "en principio, la obra de arte ha sido siempre reproducible” (Benjamin 2003[1936]: 39), ayudan a entender el engaño de Wengrow. Mientras que este carga las tintas sobre la segunda parte del título del ensayo (la reproductibilidad), el énfasis de Benjamin está sobre la primera parte (la obra de arte). No es por desconocimiento histórico que Benjamin decide comenzar su recuento por los grabados en madera medievales y las litografías modernas, sino porque para él los ejemplos que da Wengrow carecen de la principal característica que una obra de arte debe poseer para ser considerada irrepetible: el aura.
El aura es lo que hace única a una obra de arte (Benjamin 2003 [1936]: 49) y la dota de un carácter sagrado. La actual era de la reproductibilidad, sumada al encuentro operado durante el siglo XIX entre masa y obra de arte, la destruye, inaugurando una coyuntura en la que se imponen una posibilidad y un desafío, respectivamente: masificar el arte, constituir un arte legítimamente proletario; y evitar que esa obra de arte sea, como todas las demás manifestaciones culturales, apropiada por el fascismo. En cuanto a la antigüedad clásica, Benjamin continúa:

Las obras de arte más antiguas surgieron, como sabemos, al servicio de un ritual que primero fue mágico y después religioso. Ahora bien, es de importancia decisiva el hecho de que esta existencia aurática de la obra de arte no llega nunca a separarse del todo de su función ritual. (2003 [1936]: 49)

Está claro que los cilindros-sello, como dispositivos administrativos y comerciales, no entran en la definición de Benjamin. El problema de él, mucho más urgente en el contexto en que lo pensó, es cómo la producción artística se convierte en una praxis de la política, y no cómo la política crea arte que puede ser reproducido mecánicamente.

Dos características de la ciudad mesopotámica le sirven a Wengrow para afirmar que los núcleos urbanos son el ámbito privilegiado de la transmisión de las imágenes monstruosas: la estandarización de la cultura material (nada más lejano de la experiencia aurática benjaminiana), y la creación de nuevas tecnologías basadas en el principio modular (2014: 70). La ciudad sería lo que Wengrow denomina una "ecología cultural"3 propicia para el desarrollo y transferencia de este tipo de imágenes.

${ }^{3}$ Wengrow atribuye este concepto a Bateson (1972), y su aplicación a los estudios visuales a Gombrich (2003 [1999]). Sin embargo, una consulta rápida de estas 
En el último capítulo (Wengrow 2014: 89-107) se propone distinguir los modos en que se da esa transmisión, y lo hace a partir de una serie de excelentes ejemplos. Estos modos él los llama "transformativo", "integrativo" y "protectivo". Mientras que los dos primeros están asociados a la transferencia y recepción de imágenes compuestas desde su origen, el último aparece recién en el I milenio a.C. (2014: 90).

El modo transformativo aparece en sociedades en contacto con factores externos. Por ejemplo, en Grecia aparecen los grifos como intrusiones provenientes de otro lado. "En gran parte de Grecia, el s. VII a.C. fue un período de mayor competencia entre élites locales, cuyas autoridades se basaban en lazos personales de lealtad, respaldados por obligaciones del parentesco y reclamos de estatus ancestral" (Wengrow 2014: 91). Por la aparente similitud entre esta descripción de la Hélade del s. VII a.C. y el Egipto Predinástico, me gustaría retomar estas ideas más adelante. Baste aclarar aquí la relación entre intercambios a larga distancia y transmisión de imágenes compuestas.

En cuanto al modo integrativo, Wengrow se refiere a la constitución de un arte intercultural, es decir, "estilos visuales de élite que combinan elementos de origen cultural diverso y que no se identifican con ninguna 'escuela' o centro particular de producción" (2014: 95). Estas imágenes no eran apropiadas y resignificadas plenamen-

obras indica que ninguno de ellos habla de "ecología cultural", un término hasta donde sé desarrollado por Julian Steward, quien la define de esta manera: "La ecología cultural se distingue de la ecología humana y social en que busca una explicación para el origen de ciertos rasgos y patrones culturales que caracterizan diferentes áreas, en lugar de derivar principios generales y aplicables a cualquier situación cultural y ambiental" (Steward 1955: 30). te, sino que mantenían su exoticidad y otredad, a veces incorporándolos a paisajes conocidos.

Por último, en la categoría del modo protectivo entran las estatuillas producidas en serie por diversas sociedades con objetivo apotropaico. La defensa de la casa o de sus habitantes era confiada a los poderes de estos compuestos, cuya producción seguía instrucciones precisas y estandarizadas.

Tras el estudio de las maneras en que la transmisión y recepción de híbridos se dio en la Antigüedad (y no sólo en la "primera etapa de reproductibilidad técnica”), el autor está preparado para aventurar algunas conclusiones. Lo que observa en todos los casos es que estos modos de transmisión están ligados a "entornos de elevado riesgo e incertidumbre" (Wengrow 2014: 106). El peligro que se cierne sobre las culturas es el de no poder asegurar las fronteras (del imperio, de la ciudad, de la casa, etc.). Por lo tanto, en este punto se puede precisar la ecología cultural en donde se da la transmisión, ya no sólo en términos de morfología sino de dinámica institucional. "El cosmos ocupado por compuestos era frágil y quebradizo, gobernado por la amenaza de las transformaciones incontroladas y confrontado por la perspectiva de corrupción, marginación o desintegración inmanentes" (Wengrow 2014: 107).

Sin embargo, encuentro un error en la discusión que propone Wengrow, y es que piensa a las "culturas" como un todo sin fisuras (y por lo tanto, en peligro de disgregarse), cuando en realidad lo que caracteriza todos los casos estudiados es precisamente la reciente aparición de jerarquías y divisiones hacia dentro de la sociedad. Creo que este es, precisamente, el hecho que hay que tomar como paradigmático del contexto de aparición de las imágenes de híbridos. Si se quiere, el urbanismo es más bien un producto del mismo 
conjunto de contingencias históricas, y de ninguna manera una causa.

Ciertamente, no es ningún pecado tomarse ciertas licencias poéticas al titular una obra, y solamente me propuse cuestionarlo como una excusa para exponer las ideas que se encuentran tras él, ideas que por otro lado resultan altamente estimulantes. En lo que resta de este trabajo me gustaría discutir y ampliar estas ideas a la luz de otro conjunto de evidencias y un herramental teórico alternativo.

6. Cada vez conocemos mejor los procesos formativos de la civilización egipcia. En particular, y comparado con algunas décadas atrás, nuestro conocimiento de la urbanización y de la iconografía de híbridos es incomparablemente superior. Ya hacia el fin de Nagada I, el incipiente conglomerado urbano de Hierakonpolis ocupaba alrededor de 30ha (Hoffman, Hamroush y Allen 1986: 181). Los otros dos principales núcleos urbanos del Predinástico, Nagada y Abydos, concentraban población más al norte, en las márgenes del Nilo a la altura de la curva de Qena. También sabemos que el urbanismo y el origen del Estado son contemporáneos y están íntimamente relacionados (Wengrow 2006: 82-83). Sin embargo, sólo a partir del surgimiento estatal es que los núcleos urbanos comienzan a desarrollarse más ampliamente (Moeller 2016: 62).

En cuanto a los animales híbridos, han sido repetidamente identificados en el registro iconográfico contemporáneo por Dirk Huyge (2002; 2004), John Darnell y Stan Hendrickx (Hendrickx, Darnell y Gatto 2012; Hendrickx, Darnell, Gatto y Eyckerman 2012; Hendrickx, Simoens y Eyckerman 2016), y poco a poco se va construyendo una firme base teórica para pensarlos (Campagno 2001; Kuhn 2011; Wengrow 2014; Berens 2015; Hendrickx y Eyckerman 2015). Un buen número de estos está presente en mangos de cuchillos de marfil (Abu Zaidan; Petrie Museum UC 16.294; Ägyptisches Museum Berlin Inv. 15.137; Fragmento K1104 de la tumba U-127, Dreyer 1998; Gebel Tarif, Cairo Museum CG 14.265; Fragmento de marfil de Hierakonpolis, Quibell y Green 1900, Pl. XVI y XXVIII.4), y menos frecuentemente aparecen en paletas cosméticas (Hendrickx et al. 2016: 521, fig. 8; Paleta de los dos perros, en Oxford AM E3924; Paleta de la Caza, Londres EA 20792; Paleta de Hierakonpolis, Manchester M.5476). Sin embargo, en este trabajo me interesa más bien analizar una serie de ejemplos menos conocidos y reproducidos, provenientes de arte rupestre predinástico.

Dentro de la complejidad del registro material predinástico, Gwenola Graff señala que el trabajo con petroglifos tiene por lo menos una ventaja con respecto a otros artefactos: siempre se sabe con precisión el lugar de procedencia (2009: 17). Por el contrario, los cuchillos predinásticos no sólo pueden haber sido transportados hasta el lugar donde fueron encontrados, sino que también pueden haber sido heredados a lo largo de generaciones enteras antes de acabar en una tumba (Kelley 1983). Por ello, un análisis que tenga en cuenta el arte rupestre es en este sentido más exacto. Y lo que revela es que no coinciden los sitios de arte rupestre que presentan híbridos [figs. 2 a 4] con los sitios de urbanismo temprano. Wadi Nag el-Birka está casi en el centro de la Curva de Qena, en un sitio que posiblemente quedara en una intersección de caminos (Darnell 2009); Wadi Abu Subeira se ubica a varios kilómetros del Nilo, en su margen oriental; mientras que Nag el-Hamdulab queda muy cerca pero en la margen opuesta; ambos, a poca distancia al norte de la moderna ciudad de Asuán.

En cuanto a la periodización, hay buenas razones para pensar que todos los ejemplos mostrados son contemporáneos del surgimiento 
estatal, y en el caso de la fig. 2 es posible incluso que se trate de una imagen de transición (Hendrickx et al. 2012a: 1073).

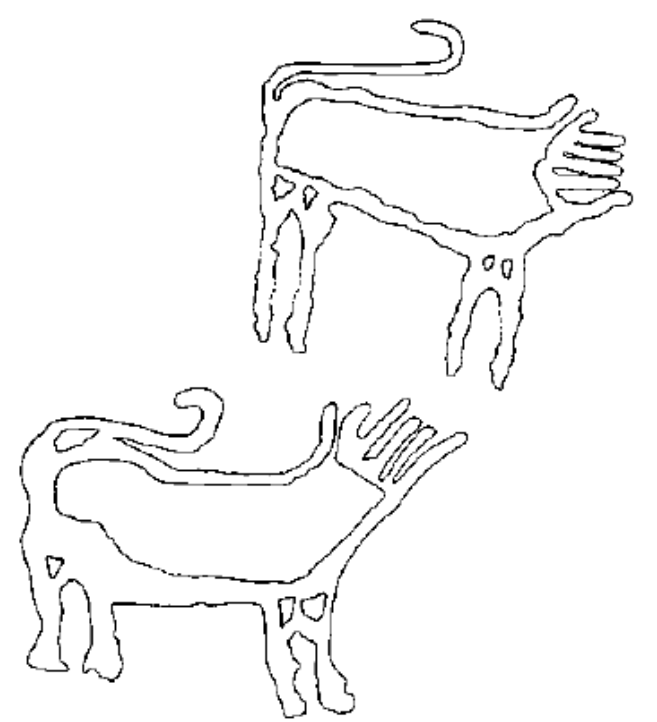

Figura 2: leones con cabeza de siluro, de Nag el-Hamdulab (Hendrickx et al. 2012b: 323, fig. 5)

Si la teoría de Wengrow fuera cierta, debería haber una coincidencia geográfica entre los sitios de aparición de los híbridos y de los núcleos urbanos. Sin embargo, esto no es así. Lo que sí se comprueba es una notable coincidencia cronológica con el momento en que surge la lógica estatal en el valle del Nilo. En este punto cabe recordar la característica más importante del urbanismo temprano, el de ser "un ámbito de composición heterogénea, a partir de la convergencia de grupos (de tramas parentales) de procedencia diversa (Campagno 2018: 67). En efecto, lo característico de la ciudad es el ser un ensamble, una combinación de tramas, y no una unidad co- mo parecería indicar Wengrow. Por otro lado, Marcelo Campagno llama la atención sobre la importancia de esta confluencia. Lo que se termina por constituir con el crecimiento de los núcleos urbanos en el área nilótica es un ámbito liminar con respecto a la trama dominante hasta el momento, la del parentesco.

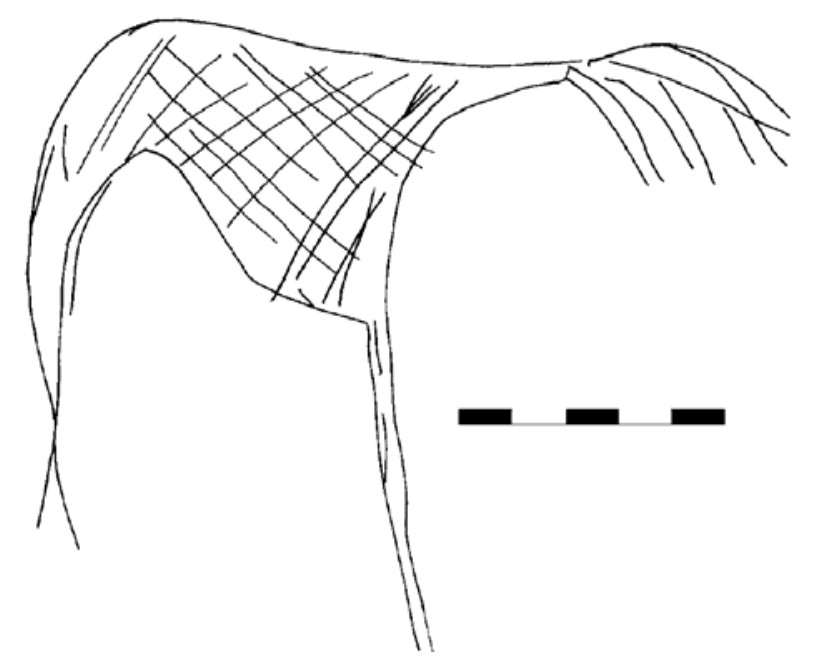

Figura 3: animal cuadrúpedo con cabeza de siluro, de Wadi Nag el-Birka (Hendrickx et al. 2012b: 324)

Por otro lado, si pensamos en la transmisión de estas imágenes, no es precisamente en la ciudad donde se da, sino justamente en su opuesto. Los cilindros-sello viajan miles de kilómetros de terreno no-urbano para llegar a algún lado donde es recibido. Aquí vale la pena citar a Wengrow: “quizás sea allí (entre las sociedades más pequeñas y dispersas de la periferia urbana) que podamos hallar los orígenes verdaderos, no sólo del militarismo sino de los valores aristocráticos, e incluso de las bases institucionales para la monarquía antigua” (2018: 42). 
Por supuesto, Wengrow se cubre de todas estas objeciones al refugiarse en la reproductibilidad mecánica. Para empezar, él mismo ofrece contraejemplos para su propio argumento. En relación a los monstruos paleolíticos, afirma, los investigadores se centraron demasiado en un pequeño cuerpo de compuestos cuando en realidad son claramente minoritarios (2014: 37). Luego, presenta el caso de los bronces chinos del II milenio a.C., donde a pesar de existir ciudades y moldes para reproducir mecánicamente un mismo motivo, los emblemáticos dragones brillan aun por su ausencia (2014: 84). Se me señalará que justamente los petroglifos son el epitome de la creación única. No hay moldes posibles para realizar incisiones en la piedra. Además, son a todas luces intransmisibles, y se trata de una objeción válida.

Lo cierto es que en Egipto hubo híbridos antes que ciudades, hubo híbridos fuera de las ciudades, entre las ciudades Y no sólo eso, sino que estos motivos no fueron "recibidos" de parte de núcleos urbanos en Mesopotamia, aunque posteriormente comenzaran a circular por el valle del Nilo los cilindros-sello como objetos de estatus. Son desarrollos autóctonos o reelaboraciones de motivos que circulaban por los espacios extraurbanos saharianos (ver Campagno 2001; Huard y Leclant 1980; Paradisi 1963).

El énfasis en el urbanismo está presente en la obra de Wengrow The Archaeology of Early Egypt (2006), donde señala la relación entre los desarrollos urbanos y los de la tecnología funeraria. Resulta lógico, siendo uno de los mayores expertos en urbanismo temprano, que cargue las tintas en este tipo de poblamientos; pero por lo menos en dos sentidos esto le es contraproducente: en primer lugar, su análisis parte de los núcleos urbanos que conoce, y al reconocer en todos ellos la existencia de imágenes de híbridos concluye que existe una relación directa entre ambos, cuando si hiciera el recorrido inverso partiendo de las imágenes híbridas no encontraría una correlación (o por lo menos se encontraría con una situación más compleja); en segundo lugar, y relacionado con lo anterior, le quita protagonismo a la imagen, que pasa a ser poco más que una moneda de cambio.

En una entrevista, Georges Didi-Huberman intentó resumir la paradoja de la imagen con las siguientes palabras: "Le pedimos demasiado poco a la imagen cuando la reducimos a una apariencia. Le pedimos demasiado cuando buscamos en ella lo real mismo" (2000). Al esperar demasiado poco de las imágenes de híbridos, Wengrow se olvida de un concepto con el que de hecho trabajó y que conoce muy bien, el de las "tecnologías del encantamiento" (Gell 1992; Wengrow 2007). Alfred Gell propone concentrarse en el objeto presentado y no en la simbología representada. En una palabra, como veremos más adelante, le preocupa entender no tanto qué "son" estas presentaciones, sino qué "hacen". Los objetos que estudia (las canoas trobriandesas) son eficaces en lo que se proponen no por un poder mágico contenido en las imágenes que muestran, sino porque son construidos con técnicas que requieren cierta destreza. Esta destreza técnica para figurar se superpondría a la destreza figurada, por ejemplo cuando en el arte rupestre egipcio se muestra a líderes prestigiosos cazando animales peligrosos (Hendrickx 2011; Maidana 2018). El trabajo invertido en la construcción de la instalación que llamamos arte rupestre le otorga la eficacia para que, por ejemplo, si se representa un animal con atributos de diversas especies, adquiera una entidad en la vida real.

La relación entre los híbridos del registro parietal protodinástico, el incipiente urbanismo y el desarrollo de la lógica estatal en el valle del Nilo estará un poco más clara luego de retomar un ejemplo brevemente mencionado más arriba, referido a la Grecia continental 
del s. VII a.C. Wengrow resume las conclusiones de James Whitley (1988) de la siguiente manera:

Whitley considera cómo, a finales del s. VIII, en Corinto, Eubea y otras partes de Grecia, este orden social establecido se interrumpió y fue transformado por la llegada de cantidades crecientes de bienes del comercio exterior y por el surgimiento de una élite cosmopolita, cuya membresía se definía principalmente mediante el uso de objetos, imágenes y prácticas no griegas [...] Para las élites locales, los objetos orientalizantes eran tanto deseables como potencialmente amenazantes, una ambivalencia que Whitley encuentra expresada con más fuerza en el Ática, donde detecta un intento de circunscribir el potencial simbólico de los bienes del comercio exterior dentro de códigos establecidos de exhibición ceremonial. (2014: 93)

Unas elites en ascenso construían su prestigio mediante la exhibición de bienes obtenidos a través del intercambio de larga distancia, y por lo tanto exóticos. Pero en el esquema de Whitley esta construcción identitaria no comienza y termina en el mercado, sino que incluye la apropiación y resignificación de imágenes de animales compuestos. Claro que Wengrow no desconoce las similitudes entre estos procesos y los que se dieron en el valle del Nilo predinástico, de modo que establece la relación entre ambas situaciones:

Se puede también establecer comparaciones con la mucho más temprana recepción de los compuestos cercano orientales en el Egipto protodinástico, a fines del IV milenio a.C., similarmente asociado a la aparicion de una cultura de élite y de nuevas instituciones; en este caso, la unificación de las "Dos Tierras" del Alto y Bajo Egipto bajo una forma de realeza sagrada que duró, en lo esencial, hasta el período grecorromano. (2014: 93)

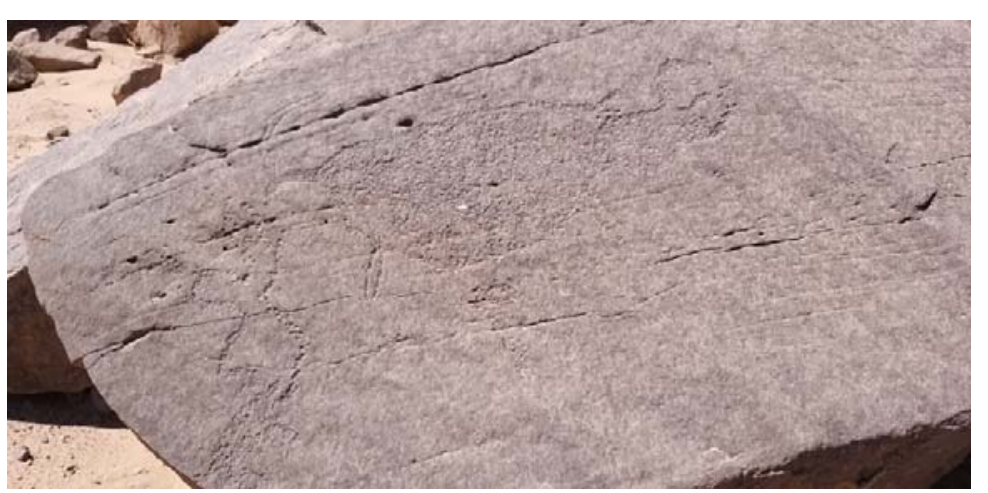

Figura 4: animal bicéfalo no identificado, posiblemente híbrido entre todo y antílope, de Wadi Abu Subeira (fotografía del autor).

En resumen, partiendo de un análisis epidemiológico de las imágenes de híbridos o compuestos y amparándose en la psicología cognitiva de Sperber, a quien debe la idea que estos compuestos son imágenes "mínimamente contraintuitivas" (Wengrow 2014: 22-23), Wengrow descarta sin embargo la hipótesis que dice que la alta transmisibilidad se da precisamente porque son contraintuitivas ( $y$ por lo tanto estimulantes). Como buen historiador, analiza los contextos de aparición y transmisión de estas imágenes, y los ubica hacia el cuarto milenio a.C. Posteriormente, encuentra contextos similares de transmisión en Grecia. En todos los casos observa una "cultura de élite" floreciente y un crecimiento de los contextos urbanos. De modo que su propia investigación le presenta dos caminos posibles. O bien explorar la hipótesis que los contextos urbanos son la clave para entender las imágenes de híbridos, o bien decantarse por el estudio atento de la forma en que esa élite construye o se apropia de las imágenes en el contexto de su aparición. El presupuesto de Wengrow es que el afianzamiento de estas élites es también un subproducto del ambiente urbano, pero en este trabajo me gustaría desarmar esta causalidad y ensayar la segunda hipótesis. 
Si es cierto que, como vimos, los híbridos que circulaban en el valle del Nilo no provenían exclusivamente de Mesopotamia, es preciso entonces modificar el esquema del autor para adaptarse mejor a la evidencia. Es probable que la relación entre híbridos y urbanismo no sea causal, sino más bien que ambos sean manifestaciones de los otros procesos que están aconteciendo en esa época. Los híbridos de leones y peces siluros observables en Nag el-Hamdulab [fig. 2] forman parte de una escena compleja, en la que también hay un íbex, dos avestruces y un gran toro, posiblemente representando al rey (Hendrickx et al. 2012b: 295), y en ese sentido relacionado con otra escena muy cercana. En esta última, un rey anónimo portando la corona blanca es seguido por dos portaestandartes en las inmediaciones de varios barcos. Acompañando a esta singular procesión también aparece un perro, metáfora recurrente del cazador en la iconografía predinástica (Hendrickx 2011). Esta escena es interesante porque, como reconocen los autores, posiblemente se trate de la más antigua representación de iconografía estatal en el área del Nilo. Lo sorprendente es que esta manifestación de estatalidad no aparece en la ciudad sino en los márgenes, en un sitio del desierto occidental. Así, se conjugan en esta instalación visual y sensorial imágenes del campo semántico de la cacería predinástica, de los animales híbridos y de la lógica estatal. Quien haya creado estas imágenes evidentemente quiso expresar un sentido que apunta más a una lógica de (auto)representación de élite que a algo propio del urbanismo y de la reproducción mecánica de imágenes. Vale la pena entonces explorar los procesos sociopolíticos que se estaban dando en la segunda parte del IV milenio a.C. en el área nilótica.

A grandes rasgos el período conocido como Predinástico se puede ubicar a lo largo del IV milenio a.C. Se trató de un período caracterizado por la concentración de población recientemente sedentarizada en algunos núcleos urbanos y por la aparición de claros signos de diferenciación social (Campagno 2001), expresada en cambios a la forma de figurar. Es notable la proliferación de imágenes que muestran a sujetos provistos de ciertos atributos de jerarquía (colas postizas, estuches fálicos, tocados, armas de guerra y cetros o cayados) cazando animales salvajes (Hendrickx 2011; 2013). Esto se observa también, de forma condensada, en las tecnologías enterratorias (Wengrow 2006), por ejemplo en tumbas en las que ciertos individuos presumiblemente relevantes dentro de la comunidad eran enterrados junto a animales salvajes, a perros y a herramientas utilizadas en la caza (Pieri y Friedman 2009). A nivel social, este período se caracterizó también por una guerra endémica (Gayubas 2016) y por el afianzamiento de un grupo dominante que basaba su posición jerárquica en una lógica distinta de la del parentesco (Campagno 2016).

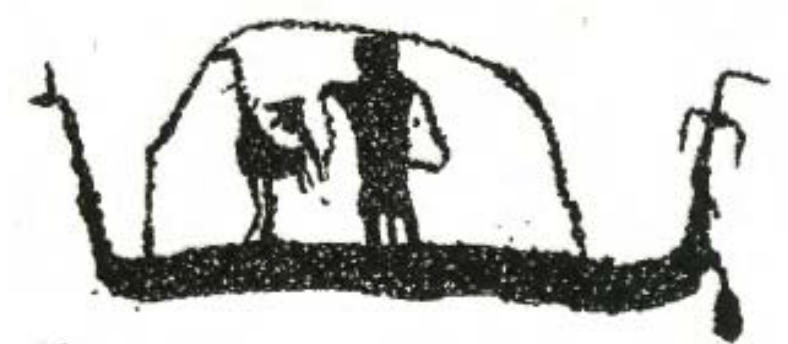

Figura 1: cazador predinástico controlando un avestruz dentro de un bote (Winkler 1938: Pl. XL no. 82)

Hans Winkler (1938) nos ha legado el calco de un petroglifo proveniente del sur de Egipto [fig. 5] que condensa visualmente esta caracterización del período. Un hombre está de pie dentro de la cabina de un bote. Simbólicamente, controla a la vez al Nilo mediante la navegación y al desierto encarnado en el avestruz que ha cazado. En su cuerpo lleva ciertos atributos de jerarquía: la cola postiza, poste- 
riormente utilizada por los reyes de Egipto, y la maza, arma de guerra y ritual. Es decir, que mantiene a raya a los elementos peligrosos, humanos y animales.

Está claro que estas imágenes (las de caza y las de híbridos), en tanto que significativamente constituidas (Hodder 2004: 28), encarnan y transmiten ideas. Podemos pensarlas como "dispositivos de memoria” (Severi 2004), vehículos para las experiencias de la vida social y cultural de estos grupos humanos ¿Qué experiencias eran trasladadas a la imagen? No todas, por supuesto. Se privilegiaban las de los "cazadores perfectos", como también era el caso de la cerámica de Ambato; y las de esas élites "eflorescentes" (Wengrow 2014: 93) que se empezaban a dotar de una identidad visual.

Según Wengrow, la adopción por parte de la burocracia urbana de una iconografía contraintuitiva y original implica una nueva forma de ver el mundo (y yo agregaría, de aprehender el mundo):

Los compuestos encapsulaban así, en llamativas formas visuales, el imperativo burocrático de confrontar el mundo, no como lo encontramos cotidianamente, compuesto por totalidades únicas y sensibles, sino como un reino imaginario compuesto por sujetos divisibles, cada uno de los cuales comprende una multitud de elementos fisionables, partes conmensurables y recombinables entre sí. (2014: 73)

Sin embargo, para la epidemiología de la cultura no se trata tanto de que la iconografía en sí sea contraintuitiva, sino de pensarla como parte de un contexto altamente contraintuitivo que es el ritual, a lo cual Wengrow no hace referencia. La pregunta sería no tanto cómo están constituidas estas imágenes, contraintuitivas o no, sino qué hacen.
Independizando a la "mirada estatal" (Scott 1998) de su pretendido anclaje urbano, yo diría que, en efecto, los experimentos iconográficos del protodinástico -la creación de híbridos, la exacerbación del peligro por ejemplo exagerando rasgos como los colmillos en ciertas representaciones de hipopótamos (Lankester 2012: 203), las composiciones de cacerías imposibles en la realidad- todos ellos son un intento de presentar el mundo no como era, sino como lo entendían las élites. Es decir, un mundo lleno de amenazas y peligros, y por lo tanto que requiriera de la existencia de esas mismas élites para asegurar el orden. Las imágenes de híbridos, como otros motivos de la iconografía de este importante período de la historia egipcia, como las canoas trobriandesas, están hechas para afectar el mundo en tanto "tecnologías de encantamiento" (Gell 1992; Fahlander 2019). Considero que, siguiendo el rastro de estas élites, y no de la reproductibilidad técnica en el ámbito urbano, tendremos más oportunidades de comprender las características de ese cosmos creado a medida de las nuevas formas de organización social que se estaban afianzando a finales del IV milenio a.C. en Egipto.

7. Si durante este trabajo hablamos sobre todo en términos de milenios, podría parecer que fue ayer cuando alrededor de 1624 Francisco de Quevedo escribió sus cuatro romances sobre "Las dos aves y los dos animales fabulosos". Estos animales imaginarios eran el basilisco, la fénix, el unicornio... y el pelícano. De este último sólo se conocían historias, no muy distintas de otras fábulas. En particular, la leyenda popular decía que los pelícanos se martirizaban haciendo sangrar su cuello para alimentar a sus hijos. Así, la pluma de Quevedo: "en jeroglíficos andas / que en asador no te he visto / te pintan pero no te empanan / toda eres cuento de niños" (1903: 342), destaca con humor su carácter imaginario y misterioso. Por supuesto, hoy sabemos que estas aves existen, y nos resulta raro ver su nombre 
entre otras bestias fantásticas, pero ciertamente no lo era en el Siglo de Oro. Lo que demuestra este pequeño ejemplo es que lo imaginario es histórico, no genético.

El libro de Wengrow responde muy bien a la cuestión del contexto en que las imágenes compuestas son transmitidas, pero elude hábilmente las preguntas clave de cómo y por qué. De una divinidad egipcia compuesta que luego adquirió popularidad en el resto del mundo mediterráneo, dice Wengrow que "saltó de las márgenes del Nilo a las ciudades costeras del Levante [...] y de allí a Creta" (Wengrow 2011b: 137). Pero las imágenes no "saltan" por sí mismas de ciudad en ciudad. Son transportadas por personas a través, y sobre todo, de mundos no-urbanos; esos "espacios vacíos" ignorados por buena parte de los académicos (véase Berenguer y Pimentel 2017), y por razones subjetivas además de sociopolíticas.

El evolucionismo cultural, hoy reencarnado en las llamadas ciencias cognitivas, falla al no reconocer un hecho sobradamente comprobado: que el cerebro humano, lejos de contener la semilla que germina en la cultura, es el producto de esta (véase Sahlins 2011). La vida humana no es la puesta en acto de potencias contenidas en módulos cognitivos, sino sobre todo improvisación (imaginación) frente a condiciones cambiantes. La inspiración de Wengrow en Rostovtzeff es reveladora de una matriz de pensamiento que tiende a colocar el motor de la vida en fuerzas suprahumanas (el mercado, la sociedad, la cultura, la mente). Ello se ve reflejado en The Origins of Monsters en la ausencia de referencias a las personas que crearon las imágenes y a los procesos por los cuales las crearon (definidos, de hecho, como "mecánicos"). Es sin embargo en las personas que encarnan la vida social que hay que buscar la respuesta a las importantes preguntas que planteó Wengrow.
En una palabra, para realmente conocer el origen de los monstruos, sería preciso partir de otro supuesto: que la cultura, es decir, la experiencia de vida de las personas, viene primero que la cognición, tanto cronológicamente (Sahlins 2011) como jerárquicamente. Son ellas las que otorgan a sus creaciones la agencia extendida (Gell 1998) para actuar en el mundo dentro de contextos que son impredecibles (Ingold 2000). Y es que, como admiten Ingold y Hallam, en definitiva "la vida no puede ser guionada" (2007: 12).

\section{REFERENCIAS}

Adams, Matthew Douglas, Tristant, Yann \& Midant-ReYnes, Béatrix (eds.) (2016), Egypt at its Origins 4. Proceedings of the Fourth International Conference "Origin of the State. Predynastic and Early Dynastic Egypt". New York 26th-30th July 2011. Orientalia Lovaniensia Analecta 205 (Lovaina: Peeters).

BALDASARRE, María I. \& DolinKo, Silvia (eds.) (2011), Travesías de la imagen. Historias de las artes visuales en la Argentina (Buenos $\mathrm{Ai}$ res: CAIA/UNTREF).

BATESON, Gregory (1972), Steps to an Ecology of Mind. Collected Essays in Anthropology, Psychiatry, Evolution, and Epistemology (Nueva Jersey: Jason Aronson Inc.).

Belting, Hans (2005), "Image, Medium, Body: A new Approach to Iconology”, Critical Inquiry, 31, 2: 302-319.

(2007), Antropología de la Imagen, trad. de Gonzalo María Vélez Espinosa (Buenos Aires: Katz).

(2009 [1990]), Imagen y culto. Una historia de la imagen anterior a la era del arte, trad. de Cristina Díez Pampliega y Jesús Espino Nuño (Madrid: Akal).

BENJAMIN, Walter (2003 [1936]), La obra de arte en la época de su reproductibilidad técnica [Urtext], trad. de Andrés E. Weikert (México: Ítaca). 
Berenguer, José \& Pimentel, Gonzalo (2017), "Introducción al estudio de los espacios internodales y su aporte a la historia, naturaleza y dinámica de las ocupaciones humanas en zonas áridas”, Estudios Atacameños, 56: 3-11.

BERENS, Vibeke (2015), Creating the Non-Existent. A materialistic approach to the development of composite animals from the Predynastic period until the Middle Kingdom (Tesis de maestría inédita: Leiden University).

BHABHA, Homi (1994), The Location of Culture (Londres: Routledge).

Bovisio, María Alba (2008), "Metáforas animales: la iconografía del poder sagrado en la plástica prehispánica del NOA”, en Fogelman (2008: 1-21).

Bovisio, María Alba (2011), "Ser o representar: acerca del estatuto de la imagen ritual prehispánica”, en Baldasarre \& Dolinko (2011: 413439)

CAMPAGNO, Marcelo (2001), “Antropozoomorfos, serpopardos, grifos. El surgimiento del Estado (y de los seres imaginarios) en el Valle del Nilo", Trabajos y Comunicaciones, 26-27: 45-58.

_ (2016), "Surgimiento de lo estatal y liderazgo local en el valle del Nilo (IV-III milenios a.C.)", en Campagno, Gallego y García Mac Gaw (2016: 15-30).

(2018), Lógicas Sociales en el Antiguo Egipto. Diez Estudios (Buenos Aires: Editorial de la Facultad de Filosofía y Letras. Universidad de Buenos Aires).

Campagno, Marcelo, Gallego, Julián \& García MaC GaW, Carlos (comps.) (2016), Regímenes Políticos en el Mediterráneo Antiguo. Estudios del Mediterráneo Antiguo. PEFSCEA, 11. (Buenos Aires: Miño y Dávila).

CHURCHER, Charles (1984), "Zoological study of the ivory knife handle from Abu Zaidan”, en Needler (1984: 152-168).

CoHEN, Jeffrey Jerome (1996), Monster Theory: Reading Culture (Minneapolis: University of Minnesota Press).
CoOTe, Jeremy \& SHELTon, Anthony Shelton (eds.) (1992), Anthropology, Art and Aesthetics (Oxford: Clarendon).

DARNELL, John Coleman (2009), "Iconographic Attraction, Iconographic Syntax, and Tableaux of Royal Ritual Power in the Pre- and ProtoDynastic Rock Inscriptions of the Theban West Desert", ArchéoNil, 19: 83-107.

DE Morgan, Jacques (1909), “L'Égypte primitive (suite)”, Revue de L'École d'Anthropologie de Paris, 19: 263-281.

DERRIDA, Jacques (2012 [1990]), "La mano de Heidegger (Geschlecht II)", trad. de Marcela Rivera Hutinel, Nombres. Revista de Filosofía, XXI, 26: 7-50.

Didi-HubERMAN, Georges (2000), "Des gammes anachroniques”, Libération, 23/11/2000. [Disponible en https://next.liberation.fr/livres/ 2000/11/23/des-gammes-anachroniques_345304; último acceso 19/9/2020]

DREYER, Günther (1998), Umm el-Qaab I. Das prädynastische Königsgrab $U-j$ und seine frühen Schriftzeugnisse (Mainz: Archäologische Veröffentlichungen 86).

FAHLANDER, Frederick (2019), "Fantastic beings and where to make them. Boats as object-beings in Bronze Age rock art", Current Swedish Archaeology, 27: 191-212.

Fogelman, Patricia (ed.) (2008), Actas del II Simposio Internacional/ III Jornadas del GERE sobre Religiosidad, Cultura y Poder (Buenos Aires: GERE).

FRANCASTEL, Pierre (1970 [1965]), La realidad figurativa, trad. de Francisco Azamor (Buenos Aires: EMECE).

Friedman, Renée (ed.) (2002), Egypt and Nubia. Gifts of the Desert (Londres: British Museum Press).

GAYUBAS, Augusto (2016), "Guerra, territorio y cambio social en el valle del Nilo preestatal”, en Campagno, Gallego \& García Mac Gaw (2016: 31-44).

GELL, Alfred (1992), "The technology of enchantment and the enchantment of technology", en Coote \& Shelton (1992: 40-66). 
(1998), Art and Agency: An Anthropological Theory (Oxford: Clarendon Press).

GOMBrICH, Ernst (1982 [1974]), The Image \& The Eye. Further Studies in the Psychology of Pictorial Representation (Singapur: Phaidon).

(2003 [1999]), Los Usos de las Imágenes. Estudios sobre la Función Social del Arte y la Comunicación Visual, (México: Fondo de Cultura Económica).

GRAFF, Gwenola (2009), Les peintures sur vases de Naqada I - Naqada II. Nouvelle aproche sémiologique de l'iconographie prédynastique (Lovaina: Leuven University Press).

HENDRICKX, Stan (2011), “L'Iconographie de la chasse dans le contexte social prédynastique”, Archéo-Nil, 20: 108-136.

(2013), "Hunting and social complexity in Predynastic Egypt", Academie Royale des Sciences d'Outre-mer, Bulletin des Séances / Koninklijke Academie voor Overzeese Wetenschappen, Mededelingen der Zittingen, 57, 2-4: 237-263.

HENDRICKX, Stan, DARNELl, John Coleman \& GATTO, Maria Carmela (2012a), "The earliest representations of royal power in Egypt: the rock drawings of Nag el-Hamdulab (Aswan)", Antiquity, 86, 334: 1068-1083.

HendrickX, Stan, DARnell, John Coleman, GATTO, Maria Carmela \& EYCKERMAN, Merel (2012b), "Iconographic and palaeographic elements dating a late Dynasty 0 rock art site at Nag el-Hamdulab", en Huyge (2012: 295-326).

HENDRICKX, Stan \& EYCKERMAN, Merel (2015), “Les animaux savages dans l'Égypte prédynastique”, en Massiera, Mathieu \& Rouffet (2015: 197-210).

Hendrickx, Stan, Friedman, Renée, CialowiCz, Krzyztof \& Chlodniki, Marek (eds.) (2004), Egypt at its Origins. Studies in Memory of Barbara Adams. Proceedings of the International Conference "Origin of the State. Predynastic and Early Dynastic Egypt", Krakow 28th Au- gust - 1st September 2002. Orientalia Lovaniensia Analecta 138 (Lovaina: Peeters).

HendrickX, Stan, Simoens, Paul \& Eyckerman, Merel (2016), “'The Facial Veins' of the bull in Predynastic Egypt”, en Adams, Tristant \& Midant-Reynes (2016: 505-533).

HODDER, Ian (2004), “The 'social' in archaeological theory: an historical and contemporary perspective”, en Meskell \& Preucel (2004: 2342).

Hoffman, Michael Allen, Hamroush, Hany A. \& Allen, Raymond O. (1986), "A model of urban development for the Hierakonpolis region from Predynastic through Old Kingdom times", Journal of the American Research Center in Egypt, 23: 175-187.

HoffMeIER, James K. y MELTZER, Edmund S. (eds.) (1983), Egyptological Miscellanies. A Tribute to Professor Ronald J. Williams (Chicago: Ares).

HuARD, Paul \& LECLANT, Jean (1980), La culture des chasseurs du nil et du Sahara (París: Société National d'Edition et de Diffusion).

HuYge, Dirk (2002), “Cosmology, Ideology, and Personal Religious Practice in Ancient Egyptian Rock Art”, en Friedman (2002: 192-206).

(2004), "A double-powerful device for regeneration: The Abu Zaidan knife handle reconsidered”, en Hendrickx, Friedman, Cialowicz y Chlodniki (2004: 823-836).

(ed.) (2012), Proceedings of the International Colloquium 'The signs of which times?' Chronological and Palaeoenvironmental Issues in the Rock Art of Northern Africa (Bruselas: Royal Academy for Overseas Sciences)

IngoLD, Tim (2000), The Perception of the Environment (Londres: Routledge).

_ (2012), "Toward an ecology of materials", Annual review of anthropology, 41: 427-442.

INGOLD, Tim \& HALlam, Elizabeth (2007), Creativity and Cultural Improvisation (Oxford: Berg). 
KARADIMAS, Dimitri (2015), "L'Anti-Chimère ou la Chimère sans Principe", Ethnographiques.org. Revue en ligne de sciences humaines et sociales, 30.

KELLEY, Allyn (1983), “A review of the evidence concerning Early Egyptian Ivory Knife Handles”, en Hoffmeier y Meltzer (1983: 95-102).

KINCAID, Harold (ed.) (2012), The Oxford Handbook of Philosophy of Social Science (Oxford: Oxford University Press)

KuHN, Robert (2011), “Überlegungen zur Herkunft und Bedeutung eines Mischwesens in der formativen Phase des alten Ägypten”, en Morenz y Kuhn (2011: 163-186).

LANKester, Francis (2012), Predynastic \& Pharaonic era Rock-Art in Egypt's Central Eastern Desert: Distribution, Dating \& Interpretation (Durham: Durham E-Theses).

LEWENS, Tim (2012), "Cultural evolution: Integration and skepticism”, en Kincaid (2012: 458-480).

Massiera, Magali, Mathieu, Bernard \& Rouffet, Frédéric (eds.) (2015), Apprivoiser le sauvage / Taming the Wild, Cahiers de l'ENiM, 11 (Montpellier: Université Paul Valéry Montpellier 3 - CNRS).

MAssumi, Brian (1993), The Politics of Everyday Fear (Minneapolis: The University of Minnesota Press).

MaydanA, Sebastián F. (2018), "Poder y violencia en los petroglifos del Egipto Predinástico. La cacería del hipopótamo como imagen de prestigio preestatal”, en Rodríguez (2018: 642-676).

Meskell, Lynn \& PreUCEL, Robert W. (eds.) (2004), A companion to social archaeology (Maiden, MA: Blackwell Publishing)

MoEller, Nadine (2016), The Archaeology of Urbanism in Ancient Egypt. From the Predynastic Period to the End of the Middle Kingdom (Nueva York: Cambridge University Press).

MorenZ, Ludwig D. \& KUHN, Robert (eds.) (2011), Vorspann oder formative Phase? Ägypten und der Vordere Orient 3500-2700 v. Chr. (Wiesbaden: Otto Harrassowitz).
MORIN, Olivier (ed.) (2017), 'The Origins of Monsters' Book Club (París: The International Cognition \& Culture Institute).

MoXEY, Keith (2008), "Visual studies and the Iconic Turn”, Journal of Visual Culture, 7, 2: 131-146.

NEEDLER, Winifred (1984), Predynastic and Archaic Egypt in The Brooklyn Museum (Brooklyn: The Museum Bookshop).

Osborne, Robin (ed.) (2007), Art's Agency and Art History (Oxford: Blackwell).

PARADISI, Ugo (1963), “La doppia protome di toro nell'arte rupestre sahariana en ella tavolozza predinastica egiziana della caccia al leone", Aegyptus, 43, 3-4: 269-277.

PIERI, Anna y FrIEDMAN, Renée (2009), “Two new tombs at HK6: The hippo hunters of Hierakonpolis", Nekhen News, 21: 13-14.

QueVEDO, Francisco (1903), Obras completas de Don Francisco de Quevedo Villegas. Edición crítica, ordenada e ilustrada. Tomo segundo y primero de las poesías, Sociedad de Bibliófilos Andaluces (Sevilla: Imprenta de E. Basco).

QUIBELL, James \& GREEN, Frederick (1900), Hierakonpolis (Egyptian Research Account \& British School of Archaeology in Egypt: Londres).

RODRÍGUEZ, Roberto (coord.) (2018), Sociedades antiguas del Creciente Fértil. Poder, ideología y violencia (Caleta Olivia: Utopías)

SAHLINS, Marshall (2011), La ilusión occidental de la naturaleza humana, trad. de Liliana Andrade Llanas y Victoria Schussheim (Buenos Aires: Fondo de Cultura Económica).

ScOTT, James (1998), Seeing Like a State. How Certain Schemes to Improve the Human Condition have Failed (New Haven: Yale University Press).

SEVERI, Carlo (2004), Il percorso e la voce: Un'antropologia della memoria (Turín: Giulio Einaudi).

SPERBER, Dan (1985), “Anthropology and psychology: towards an epidemiology of representations", Man, 20, 1: 73-89. 
(1996), Explaining Culture. A Naturalistic Approach (Oxford: Blackwell Publishing).

STEWARD, Julian (1955), Theory of Culture Change. The Methodology of Multilinear Evolution (Chicago: University of Illinois Press).

WENGROW, David (2006), La arqueología del Egipto arcaico. Transformaciones sociales en el noreste de África (10.000 - 2.650 a.C.), trad. de María José Aubet (Barcelona: Bellaterra).

(2007), "Enchantment and sacrifice in Early Egypt", en Osborne (2007: 28-41).

_ (2011a), "Gods and monsters: Image and cognition in Neolithic societies”, Paléorient, 37, 1: 153-163.

_ (2011b), "Cognition, materiality and monsters: The cultural transmission of counter-intuitive forms in Bronze Age societies", Journal of Material Culture, 16, 2: 131-149.

(2014), The origins of monsters. Image and cognition in the First Age of Mechanical Reproduction". The Rostovtzeff Lectures (Princeton: Princeton University Press).

(2017), "The Origins of Monsters: A Précis", en Morin (2017: 2-17).

(2018), "The origins of civic life - A global perspective", Origini. Preistoria e Protoistoria delle Civiltà Antiche, XLII: 25-44.

Whitley, James (1988), "Early States and Hero Cults: a reappraisal”, Journal of Hellenic Studies, 108: 173-182.

WiNkLeR, Hans (1938), Rock-Drawings of Southern Upper Egypt I (Londres: Egypt Exploration Society). 